\title{
Focus on metabolism, acute kidney injury and its influence on systemic organs
}

\author{
Michael Darmon ${ }^{1,2^{*}}$, Eric Hoste ${ }^{3,4}$ and Miet Schetz ${ }^{5}$
}

(0) 2020 Springer-Verlag GmbH Germany, part of Springer Nature

Acute kidney injury, interaction with distant organs, metabolic disturbances and renal replacement therapy (RRT) encompass vast areas of research. Recent publications once again prove this field of research to be active while underlining remaining areas of uncertainty.

\section{Acute kidney injury}

Acute kidney injury (AKI) can be viewed as a syndrome encompassing various pathophysiological mechanisms and variable degrees of renal dysfunction. It is currently defined by imperfect biomarkers. Multiple subtypes, recovery patterns and definitions have led to an increasing complexity in apprehending AKI patients [1]. In this line, Bhatraju et al. performed a latent class analysis, a technique to identify subtypes of patients, in two datasets. They identified two distinct subphenotypes of AKI including a phenotype having more severe kidney dysfunction, being associated with sepsis, ARDS and increased norepinephrine use [2]. Interestingly, these phenotypes were associated with distinct patterns of endothelial activation and inflammation, and with both 7-day non-recovery of kidney function and 28-day mortality. More importantly, the less-severe subtype of AKI showed a benefit from vasopressin therapy, in contrast to the more severe form of AKI suggesting these patterns may help in stratifying AKI phenotypes that benefit from a given intervention [2].

Limited data exist on AKI in trauma patients [3]. In a systematic review of aggregated data, Søvik et al. evaluated 24 observational studies with a total of 25,182 patients. The analysis revealed a relatively low rate of AKI

*Correspondence: michael.darmon@aphp.fr

${ }^{1}$ Medical Intensive Care Unit, APHP, Hôpital Saint-Louis, 1 Avenue Claude Vellefaux, 75010 Paris, France

Full author information is available at the end of the article
(24\%) and severe AKI (4\%) when compared to the general ICU population [4]. Substantial heterogeneity was noted which may be ascribed to differences in case mix, followup period or AKI definition across studies. Although AKI and AKI severity were strongly associated with outcome, a lack of data regarding long-term prognosis and resource consumption was noted by the authors [4].

Beyond cardiorenal syndrome, only low-level-evidence studies in humans and experimental settings have confirmed potential interactions between the kidney and distant organs. In a recent expert statement, the ADQI group reviewed both existing evidences and potential mechanisms of lung-kidney interaction [5]. More importantly, they have underlined an increasing complexity in the observed interactions consequent to increasing complex organ support, concomitant extra-corporeal life support and RRT. Recommendation for both clinical practice and for future research was formulated.

Last, optimal management of patients at risk of AKI is still debated. Microcirculatory dysregulation may explain an important part of renal hypoperfusion, and transfusion may be a therapeutic approach in this regard [6]. Since both anemia and transfusion may contribute to AKI, Garg et al., in a predefined substudy of a randomized trial in cardiac surgery patients [7], assessed the impact of a restrictive versus a liberal transfusion on kidney function. In the 4531 patients included in this study, the authors demonstrated a restrictive strategy to be safe with regard to the risk of AKI or death, without interaction with the preexisting chronic renal dysfunction [8].

\section{Metabolic disturbances and fluid balance}

Zafrani et al. [9] provided a nice overview on tumor lysis syndrome (TLS). Tumor cell destruction either spontaneous or resulting from cancer treatment may lead to TLS and subsequently AKI. Volume expansion with saline at a dose of $3 \mathrm{~L} / \mathrm{m} 2 / \mathrm{d}$ is the cornerstone therapy for TLS along 
with urate oxidase or prophylactic allopurinol for low- or intermediate-risk patients. Urine alkalization and diuretics are no longer recommended. Hemodialysis is efficient in removal of potassium, phosphate and uric acid. Since rebound may occur, subsequent continuous RRT or hybrid therapies may be preferable.

Legrand et al. [10] discussed the effects of acute brain injury on water and sodium handling, and on kidney function. Hyponatremia may be a consequence of water retention due to inappropriate ADH secretion (SIADH) or of cerebral salt wasting syndrome (CSWS) due to release of natriuretic peptides or pressure diuresis. Restricting free water and hypertonic saline is the firstline treatment, with hypertonic saline being particularly important for the correction of hypovolemia in CSWS. Oral urea can be considered for less-severe SIADH. Avoiding high blood pressure reduces pressure-induced natriuresis. Conversely, hypernatremia is usually iatrogenic due to infusion of hypertonic saline for intracranial pressure control or to mannitol-induced osmotic diuresis. In patients with hypernatremia, mannitol should be titrated to diuresis or osmolar gap. Excessive hypernatremia requires careful administration of free water.

Van Regenmortel et al. [11] reopened the debate on (the sodium content of) maintenance fluids. In a randomized trial performed in 70 adult thoracic surgery patients, they compared fluids containing $54 \mathrm{mmol} / \mathrm{L}$ of sodium (Na54) to fluid containing $154 \mathrm{mmol} / \mathrm{L}$ (Na154) administered at a fixed rate of $27 \mathrm{ml} / \mathrm{kg} / \mathrm{d}$. Na154 patients had a more positive fluid balance $(1369 \mathrm{ml}$ at $72 \mathrm{~h})$, more clinical fluid overload and more hyperchloremia, whereas Na54 patients experienced more frequent mild hyponatremia without difference in moderate-to-severe hyponatremia. Of note, Na154 patients had higher NGAL levels, suggesting more kidney damage. The clinical impact of this feasibility trial remains unclear, and larger studies are needed to answer the question of the optimal maintenance fluid in ICU patients.

Joannidis et al. [12] discussed ten myths about frusemide. Frusemide is indicated in fluid overload, but it does not cause or prevent AKI. It also does not prevent RRT or help to wean RRT. In heart failure patients, diureticinduced decongestion may cause pseudo-worsening renal function that should not prompt cessation of diuretics if congestion persists. Finally, continuous dosing does not alter hard endpoints, but leads to better-controlled diuresis.

\section{Renal replacement therapy}

In a secondary analysis of the RENAL trial, Murugan et al. [13] showed that high net fluid removal rates (median $>1.75 \mathrm{~m} / \mathrm{kg} / \mathrm{h}$ ) are independently associated with higher $90 \mathrm{~d}$ mortality compared with lower fluid removal $(<1.01 \mathrm{ml} / \mathrm{kg} / \mathrm{h})$. A possible mechanism to explain these findings is RRT-induced hypovolemia and hypotension. In this light, Douvris et al. [14] reviewed the mechanisms underlying hypotension during RRT and concluded that although net ultrafiltration represents an important contributor, it is certainly not the only mechanism. Impaired refilling of the vascular compartment is another cause of intravascular hypovolemia and may result from the underlying disease (loss of vascular integrity and hypoalbuminemia-induced low oncotic pressure) but also from fluid shifts caused by high small-solute clearance-induced osmolality changes. Furthermore, several RRT-related mechanisms may impair systolic and diastolic function and reduce vascular tone. Most of these mechanisms are expected to be more at play during intermittent dialysis compared with continuous RRT. The most important conclusion from this excellent review is

Table 1 Recent advances in field of acute kidney injury

\begin{tabular}{|c|c|c|}
\hline Where do we come from & New knowledge & Future challenges \\
\hline Heterogeneity of AKI & Identification of AKI subphenotypes & Prospective validation in external cohorts \\
\hline Few data in trauma patients & $\begin{array}{l}\text { Moderate incidence of } \mathrm{AKI} \text { and high prognostic } \\
\text { impact }\end{array}$ & $\begin{array}{l}\text { Unknown long-term outcome and economic } \\
\text { implications }\end{array}$ \\
\hline Microcirculatory dysregulation & No influence of RBC transfusion strategy on AKI & $\begin{array}{l}\text { Validation of dedicated microcirculatory interven- } \\
\text { tions }\end{array}$ \\
\hline $\begin{array}{l}\text { Creep fluid and prognostic impact of fluid } \\
\text { overload }\end{array}$ & $\begin{array}{l}\text { Low Na maintenance fluid is safe and reduces } \\
\text { fluid overload }\end{array}$ & $\begin{array}{l}\text { Do we need maintenance fluid and should it } \\
\text { contain sodium? }\end{array}$ \\
\hline Prognostic impact of fluid overload & $\begin{array}{l}\text { High net UF rate during RRT is associated with } \\
\text { poor outcome }\end{array}$ & $\begin{array}{l}\text { Delineate whether this is a causal relationship and } \\
\text { identify optimal UF }\end{array}$ \\
\hline Poor hemodynamic tolerance of RRT & $\begin{array}{l}\text { RRT-induced hypotension may be due to other } \\
\text { factors than net UF }\end{array}$ & $\begin{array}{l}\text { Test interventions to predict and prevent hypo- } \\
\text { tension }\end{array}$ \\
\hline $\begin{array}{l}\text { Uncertain risk of dialysis catheter-related infec- } \\
\text { tion }\end{array}$ & $\begin{array}{l}\text { Infection risk may be higher than with central } \\
\text { venous catheter }\end{array}$ & $\begin{array}{l}\text { Identify and implement preventive measures in } \\
\text { real-life settings }\end{array}$ \\
\hline Contrast media toxicity may be over-estimated & Matched cohort fails to show any association & $\begin{array}{l}\text { RCT in high-risk patients with intermediate benefit } \\
\text { of contrast media infusion }\end{array}$ \\
\hline
\end{tabular}


that not every hypotension during RRT should lead to a reduction in fluid removal but should instead prompt an investigation of the underlying cause and appropriate measures.

Another complication of RRT is infection related to the dialysis catheter. Using the data from four multicenter RCT's, Buetti et al. [15] compared the infection risk of dialysis and central venous catheters and, after adjustment for confounders, showed that within the first 7 days, the daily risk of catheter colonization and major catheter-related infection was significantly higher with dialysis catheters, suggesting the need for targeted prevention strategies in this early period.

The "attributable" nephrotoxicity of contrast media has been the subject of debate over the last years [16]. A further argument is provided by a retrospective analysis of a large Japanese inpatient database of 10,401 patients with septic AKI requiring RRT who had a CT scan on admission [17]. Comparison of patients exposed or unexposed to contrast did not show a difference in hospital mortality, RRT dependence at hospital discharge or duration of RRT requirement. This was the case in an unmatched comparison and after propensity-score matching of 3485 patients.

Although summarized studies provided sizable acquired knowledge, each of them has remaining questions and associated future challenges (Table 1).

\begin{abstract}
Author details
${ }^{1}$ Medical Intensive Care Unit, APHP, Hôpital Saint-Louis, 1 Avenue Claude Vellefaux, 75010 Paris, France. ${ }^{2}$ ECSTRA Team, UMR 1153, Center of Epidemiology and Biostatistics, INSERM, Université de Paris, Paris, France. ${ }^{3}$ Department of Intensive Care Medicine, Ghent University Hospital, Ghent University, C. Heymanslaan 10, 9000 Ghent, Belgium. ${ }^{4}$ Research Foundation-Flanders (FWO), Brussels, Belgium. ${ }^{5}$ Clinical Department and Laboratory of Intensive Care Medicine, Division of Cellular and Molecular Medicine, KU Leuven University, Herestraat 49, B3000 Louvain, Belgium.
\end{abstract}

\section{Funding}

None

\section{Compliance with ethical standards}

\section{Conflicts of interest}

M. Darmon has received fees from Sanofi MSD, Gilead-Kite and Astellas, and research support from MSD. The other authors declare having no conflict of interest related to this manuscript.

\section{Publisher's Note}

Springer Nature remains neutral with regard to jurisdictional claims in published maps and institutional affiliations.

Received: 12 February 2020 Accepted: 17 March 2020

Published online: 27 March 2020
References

1. James MT, Levey AS, Tonelli M et al (2019) Incidence and prognosis of acute kidney diseases and disorders using an integrated approach to laboratory measurements in a universal health care system. JAMA Netw Open 2:e191795. https://doi.org/10.1001/jamanetworkopen.2019.1795

2. Bhatraju PK, Zelnick LR, Herting J et al (2019) Identification of acute kidney injury subphenotypes with differing molecular signatures and responses to vasopressin therapy. Am J Respir Crit Care Med 199:863872. https://doi.org/10.1164/rccm.201807-13460C

3. Haines RW, Harrois A, Prowle JR et al (2019) Deserved attention for acute kidney injury after major trauma. Intensive Care Med 45:907-908. https:// doi.org/10.1007/s00134-019-05609-x

4. Søvik S, Isachsen MS, Nordhuus KM et al (2019) Acute kidney injury in trauma patients admitted to the ICU: a systematic review and metaanalysis. Intensive Care Med 45:407-419. https://doi.org/10.1007/s0013 4-019-05535-y

5. Joannidis M, Forni LG, Klein SJ et al (2019) Lung-kidney interactions in critically ill patients: consensus report of the Acute Disease Quality Initiative (ADQI) 21 Workgroup. Intensive Care Med. https://doi.org/10.1007/ s00134-019-05869-7

6. Legrand M, Ait-Oufella H, Ince C (2018) Could resuscitation be based on microcirculation data? Yes. Intensive Care Med 44:944-946. https://doi. org/10.1007/s00134-018-5121-0

7. Mazer CD, Whitlock RP, Fergusson DA et al (2017) Restrictive or liberal redcell transfusion for cardiac surgery. N Engl J Med 377:2133-2144. https:// doi.org/10.1056/NEJMoa1711818

8. Garg AX, Badner N, Bagshaw SM et al (2019) Safety of a restrictive versus liberal approach to red blood cell transfusion on the outcome of AKI in patients undergoing cardiac surgery: a randomized clinical trial. J Am Soc Nephrol JASN 30:1294-1304. https://doi.org/10.1681/ASN.2019010004

9. Zafrani L, Canet E, Darmon M (2019) Understanding tumor lysis syndrome. Intensive Care Med 45:1608-1611. https://doi.org/10.1007/s0013 4-019-05768-x

10. Legrand M, Sonneville R (2019) Understanding the renal response to brain injury. Intensive Care Med 45:1112-1115. https://doi.org/10.1007/ s00134-019-05685-z

11. Van Regenmortel N, Hendrickx S, Roelant E et al (2019) 154 compared to $54 \mathrm{mmol}$ per liter of sodium in intravenous maintenance fluid therapy for adult patients undergoing major thoracic surgery (TOPMAST): a singlecenter randomized controlled double-blind trial. Intensive Care Med 45:1422-1432. https://doi.org/10.1007/s00134-019-05772-1

12. Joannidis M, Klein SJ, Ostermann M (2019) 10 myths about frusemide. Intensive Care Med 45:545-548. https://doi.org/10.1007/s0013 4-018-5502-4

13. Murugan R, Kerti SJ, Chang C-CH et al (2019) Association of net ultrafiltration rate with mortality among critically III adults with acute kidney injury receiving continuous venovenous hemodiafiltration: a secondary analysis of the randomized evaluation of normal versus augmented level (RENAL) of renal replacement therapy trial. JAMA Netw Open 2:e195418. https:// doi.org/10.1001/jamanetworkopen.2019.5418

14. Douvris A, Zeid K, Hiremath S et al (2019) Mechanisms for hemodynamic instability related to renal replacement therapy: a narrative review. Intensive Care Med 45:1333-1346. https://doi.org/10.1007/s00134-019-05707 $-w$

15. Buetti N, Ruckly S, Lucet J-C et al (2019) Short-term dialysis catheter versus central venous catheter infections in ICU patients: a post hoc analysis of individual data of 4 multi-centric randomized trials. Intensive Care Med 45:1774-1782. https://doi.org/10.1007/s00134-019-05812-w

16. Mehran R, Dangas GD, Weisbord SD (2019) Contrast-associated acute kidney injury. N Engl J Med 380:2146-2155. https://doi.org/10.1056/NEJMr a1805256

17. Miyamoto Y, Iwagami M, Aso S et al (2019) Association between intravenous contrast media exposure and non-recovery from dialysis-requiring septic acute kidney injury: a nationwide observational study. Intensive Care Med 45:1570-1579. https://doi.org/10.1007/s00134-019-05755-2 